\title{
The Correlation between Mathematics and Physics Achievement of Senior High School Students
}

\author{
Jihe Chen ${ }^{1}$, Jerito Pereira ${ }^{1}$, Ying Zhou ${ }^{1}$, Xinxin Li $^{1}$, Maximus Tamur ${ }^{2}$, Syaharuddin ${ }^{3}$ \\ ${ }^{1}$ Guangxi Normal University \\ ${ }^{2}$ Universitas Katolik. Indonesia Santu Paulus Ruteng \\ ${ }^{3}$ Universitas Muhammadiyah Mataram \\ jeritopereira@gmail.com
}

\begin{abstract}
Physics and mathematics are the two most closely related natural rudimentary subjects. In physics, students often need to rely on rigorous mathematical reasoning and argumentation and use various mathematical methods for investigation, reasoning, calculus, test, and discussion, but students often appear in these difficulties. This research aims to explain the influence of mathematics achievement on physics achievement from the high school mathematics achievement and physics achievement. The results of math and physics in the first semester of 6 classes of senior high school student's grade 12 were selected, and the data were analyzed with SPSS.22 software, and three students of different learning abilities were interviewed in detail. The innovation of this paper lies in the use of hierarchical research methods to compare classes of mathematics achievement and physics achievement. The conclusions are (1) in objective level, there is a positive linear relationship between math achievement and physics achievement; (2) on the subjective level, students accept the view that the performance of mathematics can promote the performance of physics; students' subjective cognition will affect their cognitive structure and learning behavior, to actively seek. for the relationship between mathematical knowledge and physical knowledge, and then slowly affect the objective level of students, and then in mathematics and physics performance, and (3) applying mathematical thinking to physics learning can improve the efficiency of learning physics. Use mathematical knowledge of trigonometry to solve the force analysis problem of physical movement. The finding shows that math scores play a significant role in physics scores. Remind us that in teaching, we should pay attention to the integration of mathematical ideas into physics learning and help students learn physics knowledge better with mathematical ideas.
\end{abstract}

Keywords: Achievement, Correlation, Mathematics, Physics

\section{INTRODUCTION}

Physics and mathematics are the two most closely related natural rudimentary subjects (Kareem \& Hussin, 2013; Kent, 2008). In the study of physics, we often need to rely on rigorous mathematical reasoning and argumentation and use various mathematical methods for investigation, reasoning, calculus, test, discussion, but students often appear in these difficulties (Yopp, 2011). One of the most common situations is that many students can list the equations according to the physical situation and physical laws but cannot solve the equations (Papadopoulos, 2019; Tam et al., 2021). On further deepening of study of physics, the application of mathematics will become more and more important, if in the middle school stage better cultivate this awareness, exercise applied mathematics knowledge to strengthen the ability of physics problem solving, also must lay a solid foundation for the future study (Högskola \& Turner, 2020).

High school students often have to learn obstacles in practical teaching because they cannot transfer mathematical knowledge to physics. Specifically: first, From the student's perspective, physical knowledge mostly not easy for students to understand is often closely related to 
mathematical knowledge, and it is difficult for students to flexibly apply mathematical knowledge to physics learning, whether at the level of ideology or in the level of concrete operation (Putra \& Heriyanto, 2020; Sari, Sutarto, Mudakir, Supeno, \& Budiarso, 2020). Take the knowledge in the mechanics' chapter as an example. The scoring rate of students is always meager (Wang, Lee, Lin, Mi, \& Yang, 2021). Carefully analysis shows that in many cases, students do not grasp the physical knowledge. For example, students know the parallelogram rule and correctly carry out orthogonal decomposition on the horizontal plane. However, when the problem becomes a force decomposition on an inclined plane, many students get confused. The main reason for the difficulty is that the knowledge of trigonometry is not good enough. In addition, the expression of geometric knowledge is also complicated, such as the correct transformation of the trajectory of the electron movement, and the process of the motion state of the object is not straightforward. So if researchers can solve this problem, students will have a significant improvement in physics learning.

Second, physics teachers do not pay enough attention to the mathematics knowledge involved in teaching and lack a systematic summary from the teaching perspective. Physics teachers always think that students have learned similar knowledge in mathematics class and overestimate the ability of students to transfer knowledge. Many students often forget basic mathematical knowledge, so they can not apply it to physics very smoothly (Ayalon, 2019; Middleton, Cai, \& Hwang, 2015; Pereira, Huang, Chen, Hermita, \& Tamur, 2020). On the contrary, if a certain amount of effort breaks through the students' difficulties in related mathematics, it may play a better effect. In addition, teachers often ignore some relatively complex derivation problems involving applied mathematical knowledge, such as calculus, in some new class teaching. Some teachers directly give up this part of knowledge so that students remember the conclusion but do not understand the logic and connotation (Juandi, Tamur, Adem, \& Pereira, 2020; Stapleton, 2011).

Third, from the perspective of the examination paper, the ability to apply mathematical knowledge to solve physical problems has become very necessary in solving the college entrance examination problems, especially in solving relatively comprehensive physical problems that are particularly prominent. In addition, this ability is also indispensable in the higher stage of physics learning so that students can realize the importance of this ability earlier, which is also very beneficial to the lifelong learning and development of students. In fact, in various cases, many physical problems can be transformed into mathematical problems, such as the critical problem in physics and the extremum problem in mathematics in many cases. By looking at the problem from different Angles, our solutions will be more flexible (Crespo \& Harper, 2020).

Suppose researchers can explain the correlation between mathematical results and physical results from the perspective of data. In that case, researchers can more clearly use mathematical knowledge to consciously solve the physical knowledge in the teaching or learning process and strengthen the organic correlation. It is of great practical significance to teachers' lesson preparation or students' independent learning to avoid thinking stuck in a particular subject. By drawing lessons from the way of thinking of different disciplines will also be of great help to our problem-solving ability and application ability (Pereira, Wijaya, Zhou, \& Purnama, 2021; Pereira, Tan, Li, \& Purnama, 2020; Xu, Wu, \& Lang, 2020).

To better study, the correlation between math scores and physics scores, this paper, under the guidance of education experts, take the final exam scores of grade 12 students in the first semester of a high school as the research object (Barham, 2012; Chen, Zhao, \& Hwang, 2021). The overall performance of this school in the local area is at an average level, and the foundation of 
mathematics and physics is relatively good. From this perspective, their overall performance in general and has completion mathematics and physics are two courses of study. Students for mathematics and physics between correlation and complementarity. have a profound experience. By talking to them, we can also understand their thoughts instinctively.

Compared with previous studies, the innovation of this study is reflected in two things. First, it will choose 30 class's and grade's students (364 students) according to the average math scores, from big to small order, and then select the rank in the class as A group 1, 2, remember as A1, A2, ranked in the 15th and the 16th class as group B, B1, B2, ranked in the 29th, the 30th class as group C, for C1 and C2. It took different math scores as the standard to examine the relationship between math scores and physics scores with the characteristics of diversity and representativeness. Secondly, it makes a comparative analysis of the difference between the mathematical mean and the physical mean. Since the mean can represent the overall level of a class, the changing trend of the mean can better reflect the overall difference of the mathematical and physical scores at different levels, and more reliable conclusions can be drawn from the overall level of the scores.

According to the introduction and observation, the researcher formulation that, 1. Objectively, is there a linear relationship between math scores and physics scores? And 2. Subjectively, do students think there is a relationship between math scores and physics scores?

\section{METHOD}

The research method used in this paper is a mixed-method, including literature analysis, statistical analysis, and interview method. After finishing the mid-term examination of the first semester of senior high school grade 12, the researchers collected students' Mathematics and physics scores as the research data. After finishing the data in Excel, SPSS 22.0 software was used for statistical analysis.

Literature analysis is the basis of scientific research. By collecting and sorting out existing research and findings, researchers can find out the progress and shortcomings of relevant research. At this stage, researchers found that many studies objectively analyzed the influence of certain factors on math learning or physics learning from the perspective of gender and region, analyzed the relationship between math achievement and physics achievement, and came to the conclusion that there was a relationship between math and physics discipline, and that math achievement could affect physics achievement. However, these studies involved external variables and did not start from mathematical and physical scores. The focus of this study was on the objectivity and universality of the data. Statistical analysis can explain the objective reality reflected in the real world from the perspective of data itself, which is objective. Statistical analysis includes a comprehensive range of methods, including primary statistical data, normality test, linearity test, regression analysis, and non-parametric test. In addition, the accuracy and speed of calculation of SPSS 22.0 are faster and more convenient than those of manual calculation. The interview method emphasizes that the relationship between variables should be explained from the subjective feelings of the interviews, or the way of thinking should be explored from people's subjective experience and that learners can flexibly apply different knowledge to different aspects after learning different knowledge through their understanding and divergence. For example, Newton thought about why apples fall to the ground naturally from the natural phenomenon and thus discovered the universal gravitation and pushed out the universal gravitation formula and applied it to physics and astronomy. 
If there is some correlation between two arbitrary variables, what methods are used to determine their correlation? If there is a linear correlation, then it means that math grades affect physics grades. Based on this question, this paper chooses to use Alpha coefficient analysis to analyze the reliability of the data, and then uses SPSS 22.0 software to analyze the basic statistics, normality test, paired sample t-test of the data, and draws the scatter diagram of the math and physics scores of each class to observe whether they are linearly correlated. The innovation of the research method lies in the reliability of the analysis data and the comprehensive analysis and test of the relationship between the mathematics scores and the physics scores of high, middle, and ordinary students, which makes the conclusion more scientific and practical.

According to their math scores, researchers divided the students into 12th grades: excellent (top 27\%), medium (middle 46\%), and average (bottom 27\%), and then selected one student from these 12th grades as the interviews. Finally, grade 12 students were randomly selected for the interview. Figure 1 shows the detailed process of the study.

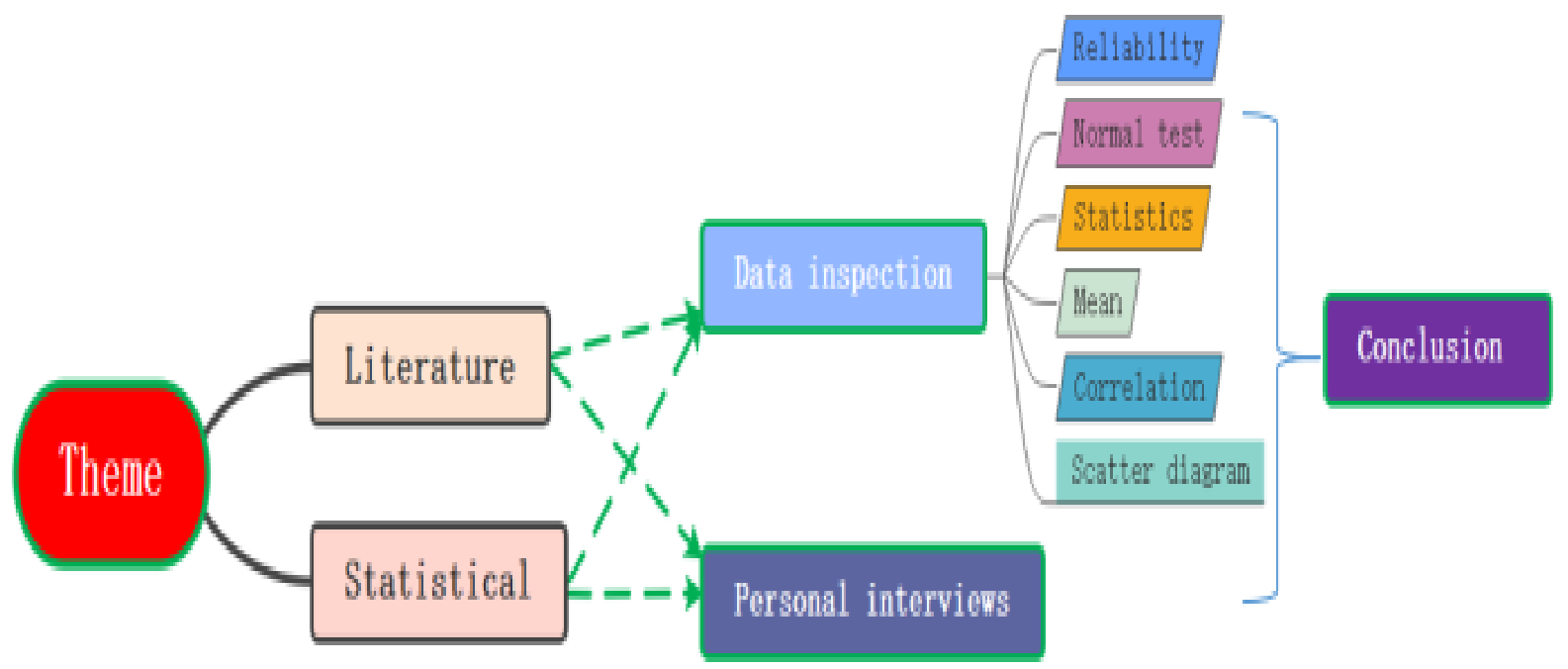

Figure 1. Research framework

Literature and statistical analysis are commonly used in data research (Brown, 2017; Chen et al., 2021; Puteh, Hanafi, \& Azman, 2017). Combined with SPSS 22.0 software, a comprehensive data analysis was conducted to explore the correlation between math scores and physics scores from multiple perspectives. Then, some students were interviewed to verify the results of data analysis from the perspective of emotion.

\section{FINDINGS}

\section{Reliability analysis}

Before the relevant research, the reliability analysis, namely reliability analysis, was carried out on the math and physics scores of the six classes. The method chosen in this paper is Alpha coefficient analysis, and Cronbach's Alpha coefficient of 6 classes is obtained. The analysis results are shown in Table 1. 
Table 1. Cronbach's coefficient

\begin{tabular}{cccl}
\hline Score & $\mathbf{N}$ & Coefficient & Level \\
\hline MA1 \& PA1 & 63 & .751 & Good \\
\cline { 2 - 4 } MA2 \& PA2 & 56 & .729 & Good \\
\cline { 2 - 4 } MB1 \& PB1 & 61 & .769 & Good \\
\cline { 2 - 4 } MB2 \& PB2 & 63 & .717 & Good \\
\cline { 2 - 4 } MC1 \& PC1 & 60 & .730 & Good \\
\cline { 2 - 4 } MC2 \& PC2 & 61 & .719 & Good \\
\hline
\end{tabular}

In terms of reliability, we can see from Table 1 that the reliability of the selected six classes all reached the level of GOOD. It shows that these six classes' math and physics scores have good reliability, which indicates that the data has research value.

\section{Normal Test}

The normal distribution is a probability distribution of continuous random variables, characterized by a left-right symmetrical shape with high in the middle and low at both ends. The result of the course examination reflects the performance of students' course level in test questions and test environment, and the factors that affect the result of students' course foundation, value-added learning results, test contents, and test environment can be regarded as random variables. Therefore, educators generally believe that the result of the course examination should conform to the normal distribution. Table 2 shows the normality test results of 6 classes.

Table 2. Normality Test Results

\begin{tabular}{cccl}
\hline Model & Sig. & Decision & Conclusion \\
\hline MA1 & 0.793 & Ho is accepted & Normal \\
\hline PA2 & 0.873 & Ho is accepted & Normal \\
\hline MA2 & 0.917 & Ho is accepted & Normal \\
\hline PA2 & 0.723 & Ho is accepted & Normal \\
\hline MB1 & 0.613 & Ho is accepted & Normal \\
\hline PB1 & 0.658 & Ho is accepted & Normal \\
\hline MB2 & 0.914 & Ho is accepted & Normal \\
\hline PB2 & 0.524 & Ho is accepted & Normal \\
\hline MC1 & 0.606 & Ho is accepted & Normal \\
\hline PC1 & 0.639 & Ho is accepted & Normal \\
\hline MC2 & 0.62 & Ho is accepted & Normal \\
\hline PC2 & 0.682 & Ho is accepted & Normal \\
\hline
\end{tabular}

As can be seen from Table 2, the significance probability of the math and physics scores of the six selected classes is more significant than 0.05 , which conforms to the normal distribution, indicating that the scores of these classes are integrated and representative, which is in line with the significance of statistical research.

\section{Basic Statistics}

Next, we analyzed the primary statistical data of the six classes, such as the average score, standard deviation, and standard error of the mean, to see the performance of these data in terms of stability. The results are shown in Table 3. 
Table 3. Sample Statistics

\begin{tabular}{cccccc}
\hline \multirow{2}{*}{1} & & Mean & $\mathbf{N}$ & Std.Deviation & Std.Error Mean \\
\cline { 2 - 6 } & MA1 & 89.2857 & 63 & 23.96868 & 3.01977 \\
\hline \multirow{2}{*}{2} & PA1 & 72.9524 & 63 & 16.12994 & 2.03218 \\
\cline { 2 - 6 } & MA2 & 88.5000 & 56 & 23.08167 & 3.08442 \\
\hline \multirow{2}{*}{3} & PA2 & 70.3214 & 56 & 16.68108 & 2.22910 \\
\cline { 2 - 6 } & MB1 & 64.4590 & 61 & 24.06143 & 3.08075 \\
\hline \multirow{2}{*}{4} & PB1 & 58.6393 & 61 & 18.47614 & 2.36563 \\
\cline { 2 - 6 } & MB2 & 61.3333 & 63 & 21.66460 & 2.72948 \\
\hline \multirow{2}{*}{5} & PB2 & 49.6825 & 63 & 17.65788 & 2.22468 \\
\cline { 2 - 6 } & MC1 & 42.0500 & 60 & 18.95975 & 2.44769 \\
\hline \multirow{2}{*}{6} & PC1 & 37.6333 & 60 & 15.38871 & 1.98667 \\
\cline { 2 - 6 } & MC2 & 44.6230 & 61 & 19.91579 & 2.54996 \\
\hline
\end{tabular}

As can be seen from Table 3, the math and physics scores of the six selected classes show three different levels of their mathematical and physical mean values. On the other hand, the standard deviation and standard error of the mean values are close. It shows that students' math and physics scores have good stability on the overall level in different levels of classes and different teaching environments. These stable data are helpful for us to eliminate experimental errors caused by some objective factors and unstable factors and help us draw conclusions that are more consistent with the facts.

\section{Difference of Mean Values between Classes}

To further examine the relationship between mathematical and physical achievements at the mean level, we drew the mean as a separate line graph and used a black line segment to represent the distance between the mathematical and physical means. The results are shown in Figure 2.

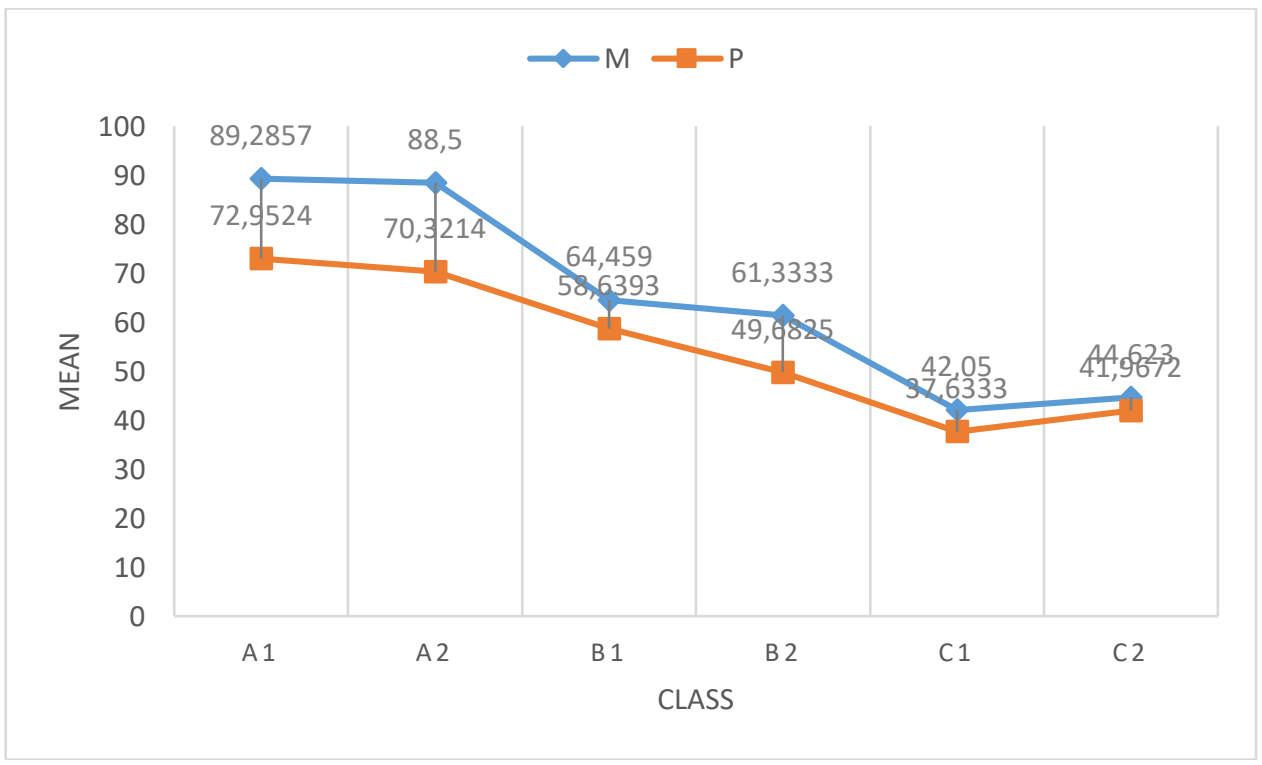

Figure 2. A line chart of the mean value 
By Figure 1, we can directly observe, when the class average math scores are higher, the average score of physics are also higher, and the mathematical average between each class as math and physics of average gap becomes smaller and smaller, it is explained in average grade level in math and physics performance are closely linked. Figure 2 is a line chart of the average scores of math and physics scores of 6 classes. Education experts and statistics experts believe that the distance of group A in math and physics performance is greater than that of group B; group C's reason is that the total marks are 150 points in math, physics performance full marks are 110. In contrast, students in math and physics have achieved excellent results, but because their total score is not the same, so the average level is not the same, so when students get high scores in both subjects, the difference between group A and group B is more significant than that between-group C. However, from the perspective of overall scores, the higher the mean value of math scores, the higher will be the mean value of physics scores, so it can be considered that there is a close relationship between math scores and physics scores.

\section{Correlation Coefficient}

The above analysis shows that math scores and physics scores have the characteristics of normality and stability, and there is a close relationship between math scores and physics scores. In order to describe the strength of this connection, the paired sample t-test was carried out on the results of six classes to obtain the correlation coefficient between the math scores and the physics scores of each class. The results are shown in Table 4.

Table 4. Paired Sample Correlation Coefficient

\begin{tabular}{lllcl}
\hline & & N & Correlation coefficient & Sig. \\
\hline 1 & MA1 \& PA1 & 63 & .649 & .000 \\
\hline 2 & MA2 \& PA2 & 56 & .624 & .000 \\
\hline 3 & MB1 \& PB1 & 61 & .607 & .000 \\
\hline 4 & MB2 \& PB2 & 63 & .570 & .000 \\
\hline 5 & MC1 \& PC1 & 60 & .587 & .000 \\
\hline 6 & MC2 \& PC2 & 61 & .575 & .000 \\
\hline
\end{tabular}

According to the correlation coefficient in Table 5, the correlation coefficient of the first three classes is more significant than 0.6. The correlation coefficient of the following three classes is also close to 0.6 , indicating a strong positive linear relationship between math and physics scores. For example, for the row of MA1 \& PA1, if the student's math score is 100 , then the student's physics score can reach $100 * 0.649=64.9$. Moreover, their significance probabilities are all 0.00 , less than 0.05 , indicating an excellent correlation between the math scores and the physics scores of these six classes, which are statistically significant.

In order to describe the solid or weak relationship between the correlation coefficient and variables, we give Table 5 as a reference.

Table 5 Relationship Between Correlation Coefficient and Two Variables

\begin{tabular}{cc}
\hline Correlation Coefficient & Degree of correlation \\
\hline$r=1$ & Complete positive correlation \\
\hline $0.7<|r|<1$ & Highly correlated \\
\hline $0.4<|r|<0.7$ & Significant correlation \\
\hline $0<|r|<0.4$ & Lowly related \\
\hline$r=-1$ & Complete negative correlation \\
\hline$r=0$ & No correlation \\
\hline
\end{tabular}




\section{Scatter Plot}

Figure 2 is the scatter diagram of the six classes, from which we can more intuitively see the linear relationship between math scores and physics scores, which intuitively confirms our conclusion. Mathematics score has no independent variable. In contrast, the physics score is the dependent variable.

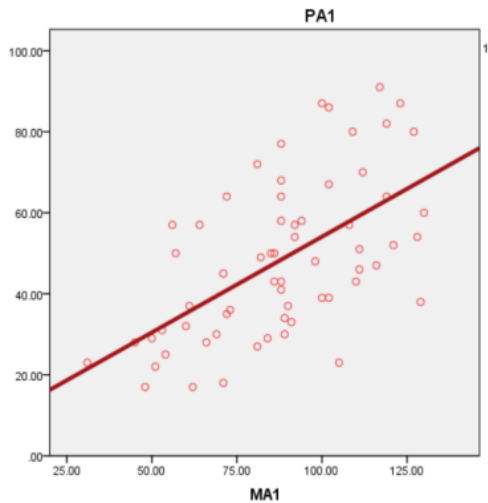

Fig. 3. a MA1 \& PA1

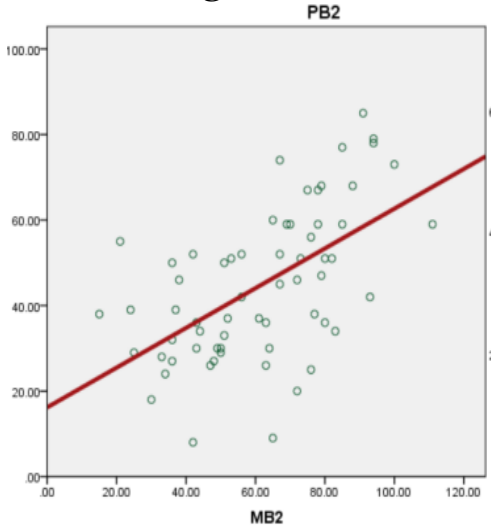

Fig.3. d MB2 \& PB2

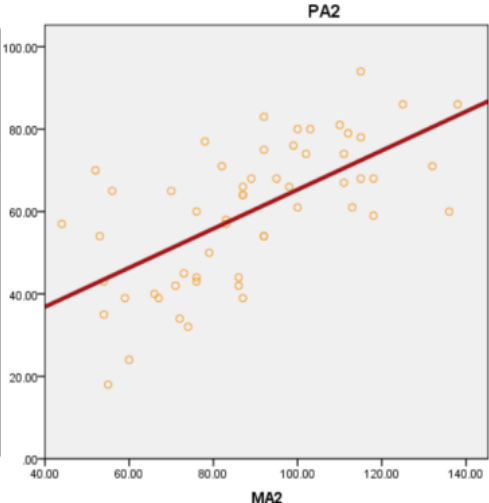

Fig. 3. b MA2 \& PA2 Fig.3. c MB1 \& PB1

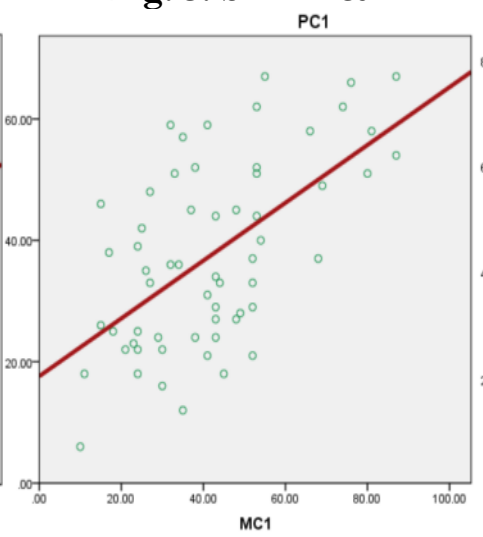

Fig.3. e MC1 \& PC1

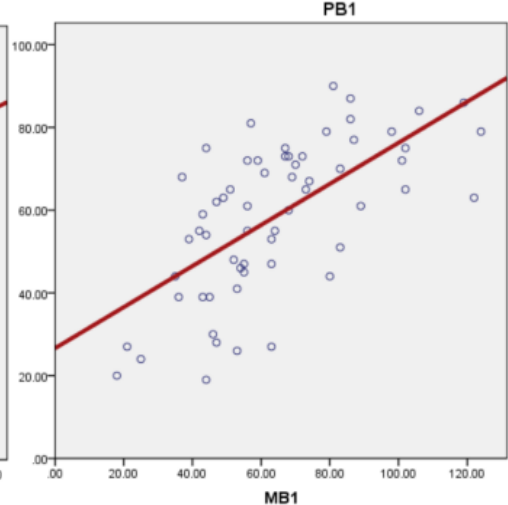

$\mathrm{PC} 2$

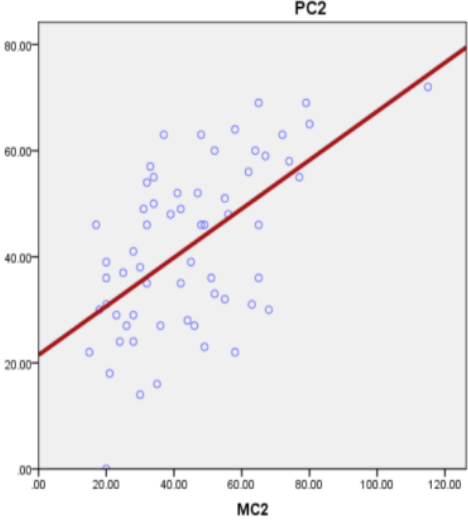

Fig.3. f MC2 \& PC2

Through the above data analysis, objectively, it can be shown that there is a positive linear relationship between math scores and physics scores. In general, the better we do in math, the higher we do in physics.

\section{Personal Interviews}

The statistical data analysis concluded that mathematics performance could affect physics performance from the objective level, which is a technical test method based on objective facts. As far as students' subjective feelings are concerned, emotion is an essential factor that affects their academic performance. Interest is the best teacher and the long-term motivation of learning because students know how to learn mathematics is conducive to promoting the study of physics, so invest more time will not feel tired, the results of the two subjects are also easy to improve. Therefore, such a point of view has formed a psychological implication in the mind of students. So for the students themselves, do they agree that learning math is helpful for the study of physics?

Based on the consideration of emotional factors, with the guidance and help of two education experts, we carefully designed six questions and selected one student from A1, B1, and C1 to answer them. The interview questions and answers are there in Table 6. 
Table 6. Students' Statements

\begin{tabular}{|c|c|c|}
\hline Questions & No. & $\begin{array}{ll} & \text { Answers } \\
\end{array}$ \\
\hline \multirow{3}{*}{$\begin{array}{l}\text { Do you think it } \\
\text { important to learn } \\
\text { maths well for physics? }\end{array}$} & 1 & $\begin{array}{l}\text { Yes, many mathematics methods can be used in physics learning. Physics } \\
\text { drawing skills are also beneficial to solve mathematical problems. There } \\
\text { are many similarities between them. }\end{array}$ \\
\hline & 2 & $\begin{array}{l}\text { Yes, most of the students who did well in math did well in physics. } \\
\text { Teachers often say that mathematical methods can be used in physics } \\
\text { learning, although I am not good at using them, I agree with this point of } \\
\text { view. }\end{array}$ \\
\hline & 3 & $\begin{array}{l}\text { Yes, there are many physics problems I have seen in learning mathematics, } \\
\text { such as simplifying algebraic expressions, calculating angles and distance } \\
\text { problems, and math problems often appear and physics-related } \\
\text { background. }\end{array}$ \\
\hline \multirow{3}{*}{$\begin{array}{l}\text { Does the physics } \\
\text { teacher supplement } \\
\text { math knowledge in } \\
\text { class? }\end{array}$} & 1 & $\begin{array}{l}\text { It is often emphasized that the teacher will show us the straightforward } \\
\text { calculation process and explain how to think from a mathematical point of } \\
\text { view when solving the problems. }\end{array}$ \\
\hline & 2 & $\begin{array}{l}\text { Occasionally, in the consolidation of knowledge, the teacher will perform } \\
\text { physics exercises and math exercises together to review and deepen our } \\
\text { impression. }\end{array}$ \\
\hline & 3 & $\begin{array}{l}\text { Generally speaking, the calculation method of mathematics is introduced } \\
\text { when the calculation is simplified, and the other time is not too much. }\end{array}$ \\
\hline \multirow{3}{*}{$\begin{array}{l}\text { Do you have difficulty } \\
\text { learning physics because } \\
\text { of your poor math } \\
\text { foundation? }\end{array}$} & 1 & $\begin{array}{l}\text { Often appeared in the past such a problem, many physics questions in } \\
\text { mathematics have seen, but just cannot remember how to do, now the } \\
\text { teacher said more feel could understand. }\end{array}$ \\
\hline & 2 & $\begin{array}{l}\text { The difficulty is mainly in the drawing. The force decomposition needs a } \\
\text { Cartesian coordinate system, and the coordinates of the center of the circle, } \\
\text { the radius, and the motion time of the electron trajectory are also closely } \\
\text { related to mathematics. All these are my difficulties. }\end{array}$ \\
\hline & 3 & $\begin{array}{l}\text { Because of my poor mathematical foundation, I often failed to find the } \\
\text { equivalence relationship in the physics problems or did not know how to } \\
\text { make a variable substitution. }\end{array}$ \\
\hline \multirow{3}{*}{$\begin{array}{l}\text { What mathematical } \\
\text { knowledge do you think } \\
\text { is closely related to } \\
\text { physical knowledge? }\end{array}$} & 1 & $\begin{array}{l}\text { Solution of triangles, trigonometric functions, and other computationally } \\
\text { immense knowledge }\end{array}$ \\
\hline & 2 & $\begin{array}{l}\text { Knowledge of systems of equations and inequalities related to the } \\
\text { relationship between variables }\end{array}$ \\
\hline & 3 & $\begin{array}{l}\text { In terms of drawing, mathematics emphasizes the combination of numbers } \\
\text { and shapes, and physics also needs to find out the relationship between } \\
\text { problems and variables, so it is often necessary to draw to express logic } \\
\text { clearly. }\end{array}$ \\
\hline \multirow{3}{*}{$\begin{array}{l}\text { In which knowledge } \\
\text { points do you want the } \\
\text { physics teacher to } \\
\text { strengthen the use of } \\
\text { mathematics } \\
\text { knowledge? }\end{array}$} & 1 & $\begin{array}{l}\text { I want to learn more about trigonometric functions. There are too many } \\
\text { trigonometric functions involved in physics problems, and I often test } \\
\text { them in big questions. I hope I can learn more about trigonometric } \\
\text { functions. }\end{array}$ \\
\hline & 2 & $\begin{array}{l}\text { When explaining the calculation, I should explain the calculation process } \\
\text { more slowly. The teacher quickly finished many complicated simplification } \\
\text { processes, and I had not yet had time to understand the principle. In } \\
\text { addition, it is best to add some examples. }\end{array}$ \\
\hline & 3 & $\begin{array}{l}\text { I hope that teachers can teach more drawing skills or use graphics to } \\
\text { express the relationship between variables. In terms of object movement } \\
\text { trajectory, they can also combine more knowledge of functions to deepen } \\
\text { their impression and understanding. }\end{array}$ \\
\hline \multirow{3}{*}{$\begin{array}{l}\text { Do you believe that if } \\
\text { you do well in math, } \\
\text { you can do better in } \\
\text { physics? }\end{array}$} & 1 & $\begin{array}{l}\text { Of course, if I were good at math, I would get more than this score in } \\
\text { physics. }\end{array}$ \\
\hline & 2 & $\begin{array}{l}\text { I believe that excellent mathematics can improve the performance of } \\
\text { physics and play a significant role in the study of other subjects and } \\
\text { thinking. }\end{array}$ \\
\hline & 3 & $\begin{array}{l}\text { I agree with this point, most of the people who do well in math also do } \\
\text { well in physics, but the students who do well in physics, do not necessarily } \\
\text { do well in math. Teachers often tell us that to strengthen the study of math, } \\
\text { math scores up, and then learning other subjects will not be difficult. }\end{array}$ \\
\hline
\end{tabular}


As can be seen from the answers in Table 6, the students' cognition all agree that learning mathematics knowledge plays a significant role in promoting physics knowledge. They also want teachers to strengthen mathematics in physics learning, especially calculation and drawing skills, and ways of finding relationships between variables. Due to the need to model the problem when solving the physical problem and then use unique methods to solve the problem, this process often uses mathematical ideas or mathematical methods. Therefore, students show great enthusiasm for the application of mathematical knowledge in physics study. From their answers can see, in the student impression if a student got very good in math, so will his physical performance better, the ubiquitous fact also psychological form a hint of the students, also suggests that the concept of the students, mathematics can indeed have a positive impact in physics learning.

\section{DISCUSSION}

Concluded that, in terms of reliability of the selected six classes, all reached the category of good. According to the correlation coefficient, the correlation coefficient of the first three classes is all greater than 0.6 , and the correlation coefficient of the following three classes is also close to 0.6 , indicating a strong positive linear relationship between math scores and physics scores. From the results of data analysis and students' subjective thinking, there is sufficient reason to believe that there is a close relationship between math and physics scores. For example, for the row of MA1 \& PA1, if the student's math score is 100 , then the student's physics score can reach $100 * 0.649=64.9$. Moreover, their significant probabilities are all 0.00 , less than 0.05 , indicating an excellent correlation between the math scores and the physics scores of these six classes, which are statistically significant.

Based on the above results, the relationship between math and physics results is very significant. These results are supported by some researchers who oppose them. For example, Barham and Chen said that students who do well in math also do well in physics because the methods used to solve math problems can solve physics problems (Barham, 2012; Chen et al., 2021). According to the previous research results, which are also supported by the interview results of some students mentioned above, students believe that the methods of learning mathematics and learning physics are very similar because if they can perfectly understand the steps of solving mathematical problems, then students' physics performance will be considerably improved.

\section{CONCLUSION}

The mathematical and physical scores of 6 classes obtained by stratified sampling show promising results in reliability analysis, normality test, paired sample t-test, and scatter chart, indicating an apparent positive correlation between the mathematical and physical scores. In interviewing students, they can tell the corresponding relationship between mathematics and physics and realize many similarities between mathematical knowledge and physics knowledge. The research results suggest that we should clarify the positive role of mathematics in promoting physics and appropriately strengthen the application of mathematical methods in the physics learning process. Therefore, objectively, there is a positive linear relationship between math achievement and physics achievement. If it can improve students' math achievement, it will also help students' physics achievement. On the subjective level, students accept the view that the performance of mathematics can promote the performance of physics, and they also hope to learn more ways to use mathematics knowledge to solve physics problems; and (3) Applying mathematical thinking to 
physics learning based on enhancing mathematical understanding can improve the efficiency of physics learning.

First, this paper only selects part of the classes in a middle school as the research object. The correlation between their math scores and physics scores remains further studied for other classes in this school or other schools. Secondly, are there any other subjects that have a particular impact on the correlation between math and physics scores? That is to say, whether the performance of other subjects will have a more noticeable effect on the improvement of physics performance? In other words, the improvement of physics scores is related to math scores and other subjects that may play a significant role, which is not discussed in this paper. Researchers look forward to furthering their studies.

\section{ACKNOWLEDGMENTS}

Research on the consistency between the mathematics test and the curriculum standard of the college entrance examination under the core literacy perspective of Innovation Project of Guangxi Graduate Education 2021 - take the mathematics volume of the general college entrance examination in the past three years as an example (NO.YCSW2021102).

\section{REFERENCES}

Ayalon, M. (2019). Exploring changes in mathematics teachers ' envisioning of potential argumentation situations in the classroom. Teaching and Teacher Education, 85, 190-203. https://doi.org/10.1016/j.tate.2019.06.019

Barham, P. J. (2012). An analysis of the changes in ability and knowledge of students taking A-level physics and mathematics over 35 years. Physics Education, 47(2), 162-168. https://doi.org/10.1088/0031-9120/47/2/162

Brown, G. T. (2017). Doctoral education in quantitative research methods: Some thoughts about preparing future scholars. Frontiers in Applied Mathematics and Statistics, 3, 25. https://doi.org/10.3389/fams.2017.00025

Chen, J., Zhao, Q., \& Huang, Y. (2021). Research On The Correlation Between Mathematics And Physics Of The Senior High School Students. Mathline: Jurnal Matematika Dan Pendidikan Matematika, 6(1), 70-80. https://doi.org/10.31943/mathline.v6i1.195

Crespo, S., \& Harper, F. K. (2020). Learning to pose collaborative mathematics problems with secondary prospective teachers. International Journal of Educational Research, 102(July 2018), 101430. https://doi.org/10.1016/j.ijer.2019.05.003

Högskola, S., \& Turner, L. E. (2020). Cultivating a research imperative : Mentoring mathematics at. Historia Mathematica, 50, 50-83. https://doi.org/10.1016/j.hm.2019.06.003

Juandi, D., Tamur, M., Adem, A. M. G., \& Pereira, J. (2020). A meta-analysis of the effects of problembased learning on students, creative thinking in mathematics. 13(229), 104-116. https://doi.org/10.20414/betajtm.v13i2.380

Kareem, M. A., \& Hussin, I. J. (2013). The Impact of Human Resource Development on Employee Performance and Organizational Effectiveness. Management Dynamics in the Knowledge Economy, 
7(3), 307-322. https://doi.org/10.25019/mdke/7.3.02

Kent, D. (2008). The Mathematical Miscellany and The Cambridge Miscellany of Mathematics: Closely connected attempts to introduce research-level mathematics in America, 1836 - 1843. 35, 102-122. https://doi.org/10.1016/j.hm.2007.12.001

Middleton, J. A., Cai, J., \& Hwang, S. (Eds.). (2015). Large-scale studies in mathematics education. Springer.

Papadopoulos, I. (2019). Using mobile puzzles to exhibit certain algebraic habits of mind and demonstrate symbol-sense in primary school students. Journal of Mathematical Behavior, 53(September 2017), 210-227. https://doi.org/10.1016/j.jmathb.2018.07.001

Pereira, J., Huang, Y., Chen, J., Hermita, N., \& Tamur, M. (2020). Learning the Concept of Absolute $V$ alue with Hawgent Dynamic Mathematics Software. 16(2), 160-169.

Pereira, J., Tan, S., Li, L., \& Purnama, A. (2020). Developing A Mathematics Learning Media to Explain Formula Of Area of Kite Using Hawgent. Indonesian Journal of Science and Mathematics Education, 3(3), 272-281. https://doi.org/10.24042/ijsme.v3i2.7391

Pereira, J., Wijaya, T. T., Zhou, Y., \& Purnama, A. (2021, May). Learning points, lines, and plane geometry with Hawgent dynamic mathematics software. In Journal of Physics: Conference Series (Vol. 1882, No. 1, p. 012057). IOP Publishing. https://doi.org/10.1088/17426596/1882/1/012057

Puteh, F., Hanafi, M., \& Azman, B. (2017). Quantitative Data Analysis : Choosing Between SPSS, PLS, and AMOS in Social Science Research. February 2018.

Putra, A., \& Heriyanto. (2020). Analysis of student's understanding about Newton's laws, in terms of perceptions to learning in senior high school. Journal of Physics: Conference Series, 1481(1). https://doi.org/10.1088/1742-6596/1481/1/012134

Sari, I. P., Sutarto, Mudakir, I., Supeno, \& Budiarso, A. S. (2020). Instructional materials for optical matter based on STEM-CP (Science, Technology, Engineering, Mathematics-Contextual Problem) to increase student critical thinking skills in high school. Journal of Physics: Conference Series, 1563(1). https://doi.org/10.1088/1742-6596/1563/1/012052

Stapleton, P. (2011). A survey of attitudes towards critical thinking among Hong Kong secondary school teachers: Implications for policy change. Thinking Skills and Creativity, 6(1), 14-23. https://doi.org/10.1016/j.tsc.2010.11.002

Tam, H., Kwok, S. Y. C. L., Hui, A. N. N., Chan, D. K., Leung, C., Leung, J., Lo, H., \& Lai, S. (2021). Children and Youth Services Review The significance of emotional intelligence to students ' learning motivation and academic achievement: A study in Hong Kong with a Confucian heritage. Children and Youth Services Review, 121(July 2020), 105847. https://doi.org/10.1016/j.childyouth.2020.105847

Wang, X., Lee, Y., Lin, L., Mi, Y., \& Yang, T. (2021). Analyzing instructional design quality and students' reviews of 18 courses out of the Class Central Top 20 MOOCs through systematic and sentiment analyses. The Internet and Higher Education, 50(January 2020), 100810. https://doi.org/10.1016/j.iheduc.2021.100810

Xu, C., Wu, L., \& Wang, S. (2020). Unsupervised Dimension Reduction for Image Classification Using Regularized Convolutional Auto-Encoder. In Advances in Intelligent Systems and Computing 
(Vol. 943, Issue 28). Springer International Publishing. https://doi.org/10.1007/978-3-03017795-9_8

Yopp, D. A. (2011). The Journal of Mathematical Behavior How some research mathematicians and statisticians use proof in undergraduate mathematics. Journal of Mathematical Behavior, 30(2), 115-130. https://doi.org/10.1016/j.jmathb.2011.01.002

\section{AUTHORS CONTRIBUTION}

\begin{tabular}{|c|c|}
\hline Author & Contribution \\
\hline Jihe Chen & Complete the writing of the article \\
\hline Jerito Pereira & $\begin{array}{l}\text { Corresponding Author. Revise the paper, including first, } \\
3^{\text {rd }}, 4^{\text {th }}, 5^{\text {th }} \text {, and } 6^{\text {th }}\end{array}$ \\
\hline Xinxin Li & Complete data collection and analysis \\
\hline Ying Zhou & Provide writing ideas and writing guidance \\
\hline $\begin{array}{l}\text { Maximus Tamur and } \\
\text { Syaharuddin }\end{array}$ & Check translations, references and recheck Grammarly. \\
\hline
\end{tabular}

